\title{
Hospitalists as Triagists: Description of the Triagist Role across Academic Medical Centers
}

\author{
Sadie Trammell Velásquez, MD ${ }^{1,2 *}$, Emily S Wang, MD 1,2 , Andrew A White, MD², \\ Jagriti Chadha, MD, MPH${ }^{4}$, Michael Mader ${ }^{1,2}$, Luci K Leykum, MD, MBA, MSc ${ }^{1,2}$, Jacqueline Pugh, MD ${ }^{1,2}$
}

${ }^{1}$ Department of Medicine, Division of General and Hospital Medicine, University of Texas Health San Antonio, San Antonio, Texas; ${ }^{2}$ South Texas Veterans Health Care System, Medicine Service, San Antonio, Texas; ${ }^{3}$ University of Washington School of Medicine, Department of Medicine, Seattle, Washington; ${ }^{4}$ University of Kentucky, Division of Hospital Medicine, Lexington, Kentucky.

From the hospitalist perspective, triaging involves the evaluation of a patient for potential admission to an inpatient service. Although traditionally done by residents, many academic hospitalist groups have assumed the responsibility for triaging. We conducted a cross-sectional survey of 235 adult hospitalists at 10 academic medical centers (AMCs) to describe the similarities and differences in the triagist role and assess the activities and skills associated with the role. Eight AMCs have a defined triagist role; at the others, hospitalists supervise residents/advanced practice providers. The triagist role is generally filled by a faculty physician and shared by all hospitalists.

We found significant variability in verbal communication practices $(P=.02)$ and electronic communication practices $(P<.0001)$ between the triagist and the current provider (eg, emergency department, clinic provider), and in the percentage of patients evaluated in person $(P<.0001)$. Communication skills, personal efficiency, and systems knowledge are dominant themes of attributes of an effective triagist. Journal of Hospital Medicine 2020;15: 87-90. (C) 2020 Society of Hospital Medicine
$\mathrm{H}$ ospital medicine has grown dramatically over the past 20 years. ${ }^{1,2} \mathrm{~A}$ recent survey regarding hospitalists' clinical roles showed an expansion to triaging emergency department (ED) medical admissions and transfers from outside hospitals. ${ }^{3}$ From the hospitalist perspective, triaging involves the evaluation of patients for potential admission. ${ }^{4}$ With scrutiny on ED metrics, such as wait times (https://www. medicare.gov/hospitalcompare/search.html), health system administrators have heightened expectations for efficient patient flow, which increasingly falls to hospitalists. ${ }^{5-7}$

Despite the growth in hospitalists' triagist activities, there has been little formal assessment of their role. We hypothesized that this role differs from inpatient care in significant ways. ${ }^{6-8}$ We sought to describe the triagist role in adult academic inpatient medicine settings to understand the responsibilities and skill set required.

\section{METHODS}

Ten academic medical center (AMC) sites were recruited from Research Committee session attendees at the 2014 Society of Hospital Medicine national meeting and the 2014 Society of General Internal Medicine southern regional meeting. The AMCs were geographically diverse: three Western, two Mid-

*Corresponding Author: Sadie Trammell Velásquez, MD; E-mail: trammellvela@uthscsa.edu; Telephone: 210-358-1944; Twitter: @trammellvela

Published online first October 23, 2019.

Find Additional Supporting Information in the online version of this article.

Received: April 30, 2019; Revised: August 31, 2019;

Accepted: September 11, 2019

(C) 2019 Society of Hospital Medicine DOI 10.12788/jhm.3327 western, two Southern, one Northeastern, and two Southeastern. Site representatives were identified and completed a web-based questionnaire about their AMC (see Appendix 1 for the information collected). Clarifications regarding survey responses were performed via conference calls between the authors (STV, ESW) and site representatives.

\section{Hospitalist Survey}

In January 2018, surveys were sent to 583 physicians who worked as triagists. Participants received an anonymous 28item RedCap survey by e-mail and were sent up to five reminder e-mails over six weeks (see Appendix 2 for the questions analyzed in this paper). Respondents were given the option to be entered in a gift card drawing.

Demographic information and individual workflow/practices were obtained. A 5-point Likert scale (strongly disagree - strongly agree) was used to assess hospitalists' concurrence with current providers (eg, ED, clinic providers) regarding the management and whether patients must meet the utilization management (UM) criteria for admission. Time estimates used $5 \%$ increments and were categorized into four frequency categories based on the local modes provided in responses: Seldom (0\%-10\%), Occasional (15\%-35\%), Half-the-Time (40\%-60\%), and Frequently (65\%-100\%). Free text responses on effective/ineffective triagist qualities were elicited. Responses were included for analysis if at least $70 \%$ of questions were completed.

\section{Data Analysis Quantitative}

Descriptive statistics were calculated for each variable. The Kruskal-Wallis test was used to evaluate differences across 
AMCs in the time spent on in-person evaluation and communication. Weighting, based on the ratio of hospitalists to survey respondents at each $\mathrm{AMC}$, was used to calculate the average institutional percentages across the study sample.

\section{Qualitative}

Responses to open-ended questions were analyzed using thematic analysis. ${ }^{9}$ Three independent reviewers (STV, JC, ESW) read, analyzed, and grouped the responses by codes. Codes were then assessed for overlap and grouped into themes by one reviewer (STV). A table of themes with supporting quotes and the number of mentions was subsequently developed by all three reviewers. Similar themes were combined to create domains. The domains were reviewed by the steering committee members to create a consensus description (Appendix 3).

The University of Texas Health San Antonio's Institutional Review Board and participating institutions approved the study as exempt.

\section{RESULTS}

\section{Site Characteristics}

Representatives from 10 AMCs reported data on a range of one to four hospitals for a total of 22 hospitals. The median reported that the number of medical patients admitted in a 24-hour period was 31-40 (range, 11-20 to $>50$ ). The median group size of hospitalists was 41-50 (range, 0-10 to $>70$ ).

The survey response rate was $40 \%(n=235)$, ranging from $9 \%-70 \%$ between institutions. Self-identified female hospitalists accounted for $52 \%$ of respondents. Four percent were $25-$ 29 years old, 66\% were $30-39$ years old, $24 \%$ were $40-49$ years old, and $6 \%$ were $\geq 50$ years old. The average clinical time spent as a triagist was $16 \%$.

\section{Description of Triagist Activities}

The activities identified by the majority of respondents across all sites included transferring patients within the hospital (73\%), and assessing/approving patient transfers from outside hospitals and clinics (82\%). Internal transfer activities reported by $>50 \%$ of respondents included allocating patients within the hospital or bed capacity coordination, assessing intensive care unit transfers, assigning ED admissions, and consulting other services. The ED accounted for an average of $55 \%$ of calls received. Respondents also reported being involved with the documentation related to these activities.

\section{Similarities and Differences across AMCs}

Two AMCs did not have a dedicated triagist; instead, physicians supervised residents and advanced practice providers. Among the eight sites with triagists, triaging was predominantly done by faculty physicians contacted via pagers. At seven of these sites, $100 \%$ of hospitalists worked as triagists. The triage service was covered by faculty physicians from 8-24 hours per day.

Bed boards and transfer centers staffed by registered nurses, nurse coordinators, house supervisors, or physicians were common support systems, though this infrastructure was organized differently across institutions. A UM review before ad- mission was performed at three institutions 24 hours/day. The remaining institutions reviewed patients retrospectively.

Twenty-eight percent of hospitalists across all sites "Disagreed" or "Strongly disagreed" that a patient must meet UM criteria for admission. Forty-two percent had "Frequent" different opinions regarding patient management than the consulting provider.

Triagist and current provider communication practices varied widely across AMCs (Figure). There was significant variability in verbal communication $(P=.02)$, with $>70 \%$ of respondents at two $A M C s$ reporting verbal communication at least half the time, but $<30 \%$ reporting this frequency at two other AMCs. Respondents reported variable use of electronic communication (ie, notes/orders in the electronic health record) across AMCs $(P<.0001)$. Half of the hospitalists use it "Seldom", $20 \%$ use it "Occasionally", and 23\% use it "Frequently".

The practice of evaluating patients in person also varied significantly across AMCs ( $P<.0001$, Figure). Across hospitalists, only $28 \%$ see patients in person about "Half-the-Time" or more.

\section{Differences within AMCs}

Variability within AMCs was greatest for the rate of verbal communication practices, with a typical interquartile range (IOR) of $20 \%$ to $90 \%$ among the hospitalists within a given AMC and for the rate of electronic communication with a typical IQR of $0 \%$ to $50 \%$. For other survey questions, the IQR was typically 15 to 20 percentage points.

\section{Thematic Analysis}

We received 207 and 203 responses (88\% and 86\%, respectively) to the open-ended questions "What qualities does an effective triagist have?' and 'What qualities make a triagist ineffective?" We identified 22 themes for effective and ineffective qualities, which were grouped into seven domains (Table). All themes had at least three mentions by respondents. The three most frequently mentioned themes, communication skills, efficiency, and systems knowledge, had greater than 60 mentions.

\section{DISCUSSION}

Our study of the triagist role at 10 AMCs describes critical triagist functions and identifies key findings across and within AMCs. Twenty-eight percent of hospitalists reported admitting patients even when the patient did not meet the admission criteria, consistent with previous research demonstrating the influence of factors other than clinical disease severity on triage decisions. ${ }^{10}$ However, preventable admissions remain a hospital-level quality metric. ${ }^{11,12}$ Triagists must often balance each patient's circumstances with the complexities of the system. Juggling the competing demands of the system while providing patient-centered care can be challenging and may explain why attending physicians are more frequently filling this role. ${ }^{13}$

Local context/culture is likely to play a role in the variation across sites; however, compensation for the time spent may also be a factor. If triage activities are not reimbursable, this could lead to less documentation and a lower likelihood that 


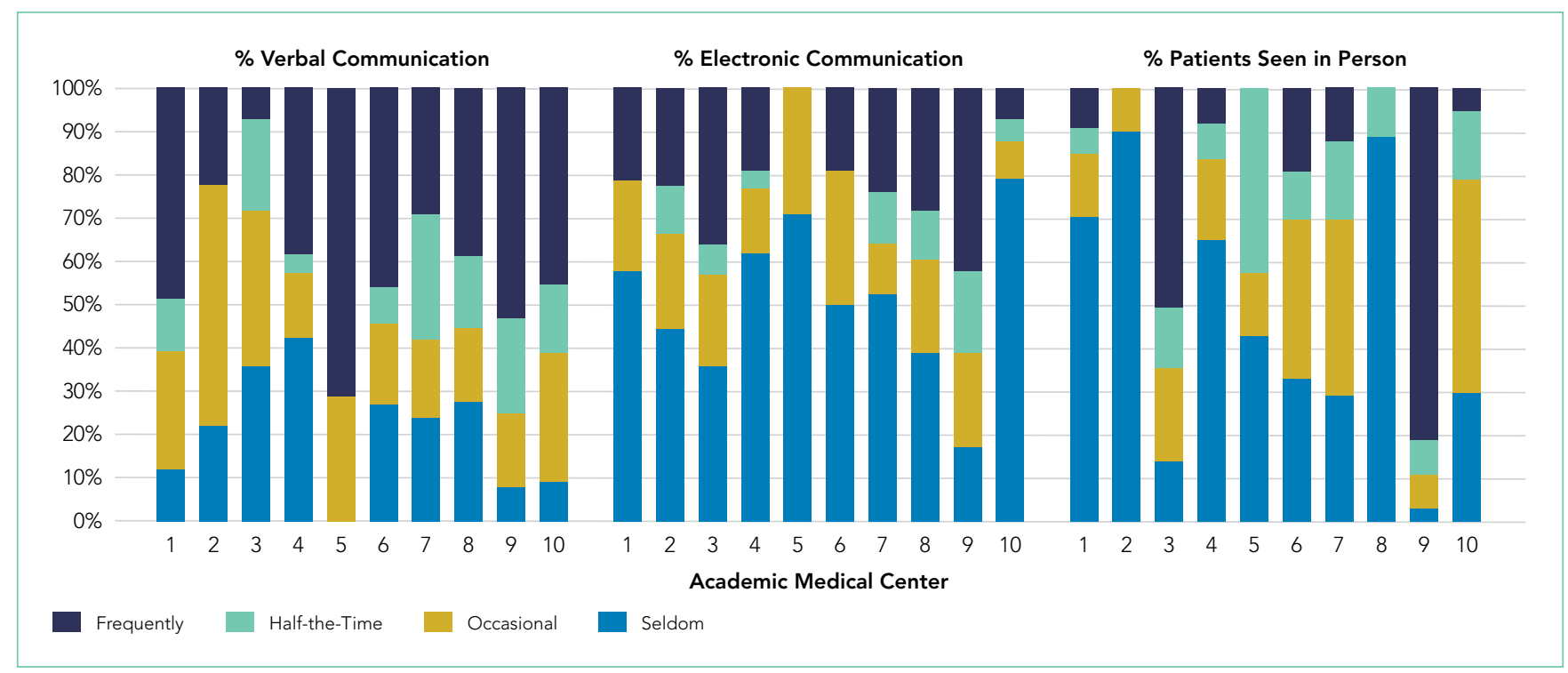

FIG. Distribution of Time Communicating Verbally vs Electronically and Patients Seen in Person, by Academic Medical Center

\section{TABLE. Effective Triagist Domains}

\begin{tabular}{|c|c|c|c|}
\hline Domain & Definition & Relevant Theme(s) & Quotes \\
\hline $\begin{array}{l}\text { Communication, negotiation, } \\
\text { and relationship skills }\end{array}$ & $\begin{array}{l}\text { This domain encompasses successful and } \\
\text { collaborative interpersonal interactions. }\end{array}$ & $\begin{array}{l}\text { Communication skills } \\
\text { Established relationships with other services } \\
\text { Negotiation skills } \\
\text { Awareness of other providers' goals and expectations }\end{array}$ & "able to build relationships and work with people" \\
\hline Organizational skills & $\begin{array}{l}\text { This domain encompasses the use of time and } \\
\text { energy in an effective way. }\end{array}$ & $\begin{array}{l}\text { Efficient }^{\mathrm{a}} \\
\text { Organized } \\
\text { Prioritizes well } \\
\text { Thorough } \\
\text { Able to see the big picture } \\
\text { Decisive }\end{array}$ & $\begin{array}{l}\text { "There is often a lot of clinical information to interpret } \\
\text { and a good triagist can do this efficiently and effectively" }\end{array}$ \\
\hline $\begin{array}{l}\text { Systems and utilization } \\
\text { management knowledge }\end{array}$ & $\begin{array}{l}\text { This domain encompasses how we get everything } \\
\text { done in our system. }\end{array}$ & $\begin{array}{l}\text { Systems knowledge } \\
\text { Knowledge of Utilization Management } \\
\text { Experienced }\end{array}$ & $\begin{array}{l}\text { "comprehensive understanding of the capabilities of the } \\
\text { hospital system in which you work" }\end{array}$ \\
\hline Attitudes regarding patients & This domain encompasses patient-centeredness. & $\begin{array}{l}\text { Patient-centered } \\
\text { Awareness of other providers goals and expectations }\end{array}$ & $\begin{array}{l}\text { "willing to back down and provide for patient needs } \\
\text { in the event of a disagreement" }\end{array}$ \\
\hline Medical skills & $\begin{array}{l}\text { This domain encompasses medical and clinical } \\
\text { judgement. }\end{array}$ & $\begin{array}{l}\text { Medical knowledge } \\
\text { Good clinical judgement } \\
\text { Physically examines } \\
\text { Experienced }\end{array}$ & "ability to gauge clinical diagnosis and stability of patient" \\
\hline Experienced & $\begin{array}{l}\text { This domain encompasses time and repeated } \\
\text { observation in an activity. }\end{array}$ & $\begin{array}{l}\text { Experienced } \\
\text { Established relationships with other services } \\
\text { Able to see the big picture } \\
\text { Confident } \\
\text { Decisive } \\
\text { Emotional intelligence }\end{array}$ & $\begin{array}{l}\text { "experience to understand what is important to look } \\
\text { at the time of triage" }\end{array}$ \\
\hline Professionalism & $\begin{array}{l}\text { This domain encompasses personal qualities and } \\
\text { traits. }\end{array}$ & $\begin{array}{l}\text { Calm } \\
\text { Patient } \\
\text { Objective } \\
\text { Confident } \\
\text { Emotional intelligence } \\
\text { Awareness of other providers' goals and expectations }\end{array}$ & $\begin{array}{l}\text { "ability to keep calm in stressful situations, both internally } \\
\text { and externally" }\end{array}$ \\
\hline
\end{tabular}


patients are evaluated in person. ${ }^{14}$ This reason may also explain why all hospitalists were required to serve as a triagist at most sites.

Currently, no consensus definition of the triagist role has been developed. Our results demonstrate that this role is heterogeneous and grounded in the local healthcare system practices. We propose the following working definition of the triagist: a physician who assesses patients for admission, actively supporting the transition of the patient from the outpatient to the inpatient setting. A triagist should be equipped with a skill set that includes not only clinical knowledge but also emphasizes systems knowledge, awareness of others' goals, efficiency, an ability to communicate effectively, and the knowledge of UM. We recommend that medical directors of hospitalist programs focus their attention on locally specific, systems-based skills development when orienting new hospitalists. The financial aspects of cost should be considered and delineated as well.

Our analysis is limited in several respects. Participant AMCs were not randomly chosen, but do represent a broad array of facility types, group size, and geographic regions. The low response rates at some AMCs may result in an inaccurate representation of those sites. Data was not obtained on hospitalists that did not respond to the survey; therefore, nonresponse bias may affect outcomes. This research used self-report rather than direct observation, which could be subject to recall and social desirability bias. Finally, our results may not be generalizable to nonacademic institutions.

\section{CONCLUSION}

The hospitalist role as triagist at AMCs emphasizes communication, organizational skills, efficiency, systems-based practice, and UM knowledge. Although we found significant variation across and within AMCs, internal transfer activities were common across programs. Hospitalist programs should focus on systems-based skills development to prepare hospitalists for the role. The skill set necessary for triagist responsibilities also has implications for internal medicine resident education. ${ }^{4}$ With increasing emphasis on value and system effectiveness in care delivery, further studies of the triagist role should be undertaken.

\section{Acknowledgments}

The TRIAGIST Collaborative Group consists of: Maralyssa Bann, MD, Andrew White, MD (University of Washington); Jagriti Chadha, MD (University of Kentucky); Joel Boggan, MD (Duke University); Sherwin Hsu, MD (UCLA); Jeff Liao, MD (Harvard Medical School); Tabatha Matthias, DO (University of Nebraska Medical Center); Tresa McNeal, MD (Scott and White Texas A\&M); Roxana
Naderi, MD, Khooshbu Shah, MD (University of Colorado); David Schmit, MD (University of Texas Health San Antonio); Manivannan Veerasamy, MD (Michigan State University).

Disclosures: There are no relationships, conditions, circumstances that present a conflict of interest.

Funding: The research reported here was supported by the Department of Veterans Affairs, Veterans Health Administration. Author salary support is provided by the South Texas Veterans Health Care System and by the Division of Hospital Medicine at the University of Texas Health San Antonio.

Disclaimer: The views expressed in this article are those of the authors and do not necessarily reflect the position or policy of the Department of Veterans Affairs.

\section{References}

1. Kisuule F, Howell EE. Hospitalists and their impact on quality, patient safety, and satisfaction. Obstet Gynecol Clin North Am. 2015; 42(3):433-446. https:// doi.org/10.1016/j.ogc.2015.05.003.

2. Wachter, RM, Goldman, L. Zero to 50,000-The 20th anniversary of the hospitalist. N Engl J Med. 2016;375(11): 1009-1011. https://doi.org/10.1056/NEJMp1607958.

3. Vasilevskis EE, Knebel RJ, Wachter RM, Auerbach AD. California hospital leaders' views of hospitalists: meeting needs of the present and future. $J$ Hosp Med. 2009;4:528-534. https://doi.org/10.1002/jhm.529.

4. Wang ES, Velásquez ST, Smith CJ, et al. Triaging inpatient admissions: an opportunity for resident education. J Gen Intern Med. 2019; 34(5):754-757. https://doi.org/10.1007/s11606-019-04882-2.

5. Briones A, Markoff B, Kathuria N, et al. A model of a hospitalist role in the care of admitted patients in the emergency department. J Hosp Med. 2010;5(6):360-364. https://doi.org/10.1002/jhm.636.

6. Howell EE, Bessman ES, Rubin HR. Hospitalists and an innovative emergency department admission process. J Gen Intern Med. 2004;19:266-268. https:// doi.org/10.1111/j.1525-1497.2004.30431.x.

7. Howell E, Bessman E, Marshall R, Wright S. Hospitalist bed management effecting throughput from the emergency department to the intensive care unit. J Crit Care. 2010;25:184-189. https://doi.org/10.1016/j.jcrc.2009.08.004.

8. Chadaga SR, Shockley L, Keniston A, et al. Hospitalist-led medicine emergency department team: associations with throughput, timeliness of patient care, and satisfaction. J Hosp Med. 2012;7:562-566. https://doi.org/10.1002/ jhm.1957.

9. Braun, V. Clarke, V. Using thematic analysis in psychology. Qualitative Research in Psychology. 2006;77-101. https://doi.org/10.1191/1478088706qp063oa.

10. Lewis Hunter AE, Spatz ES, Bernstein SL, Rosenthal MS. Factors influencing hospital admission of non-critically ill patients presenting to the emergency department: a cross-sectional study. J Gen Intern Med. 2016;31(1):37-44. https://doi.org/10.1007/s11606-015-3438-8.

11. Patel KK, Vakharia N, Pile J, Howell EH, Rothberg MB. Preventable admissions on a general medicine service: prevalence, causes and comparison with $\mathrm{AHRQ}$ prevention quality indicators-a cross-sectional analysis. J Gen Intern Med. 2016;31(6):597-601. https://doi.org/10.1007/s11606-016-3615-4.

12. Daniels LM1, Sorita A2, Kashiwagi DT, et al. Characterizing potentially preventable admissions: a mixed methods study of rates, associated factors, outcomes, and physician decision-making. J Gen Intern Med. 2018;33(5):737744. https://doi.org/10.1007/s11606-017-4285-6.

13. Howard-Anderson J, Lonowski S, Vangala S, Tseng CH, Busuttil A, Afsar-Manesh N. Readmissions in the era of patient engagement. JAMA Intern Med. 2014;174(11):1870-1872. https://doi.org/10.1001/jamainternmed.2014.4782.

14. Hinami K, Whelan CT, Miller JA, Wolosin RJ, Wetterneck TB, Society of Hospital Medicine Career Satisfaction Task Force. Job characteristics, satisfaction, and burnout across hospitalist practice models. J Hosp Med. 2012;7(5):402410. https://doi.org/10.1002/jhm.1907 